\title{
Yüksek Hızlı Hatlarda Granüler Altbalast Yerine Asfalt Tabaka Kullanımının Sonlu Elemanlarla Modellenmesi
}

\author{
Cahit GÜRER ${ }^{* 1}\left(\mathbb{D}\right.$, Tugçe AKILLI TÖRER ${ }^{2} \mathbb{D}$, Kubilay ASLANTAŞ$^{3}{ }^{\mathbb{D}}$ \\ ${ }^{1}$ Afyon Kocatepe Üniversitesi, Mühendislik Fakültesi, Inşaat Mühendisliği Bölümü, Afyonkarahisar, \\ Türkiye \\ ${ }^{2}$ TCDD Genel Müdürlüğü, Modernizasyon Dairesi Başk., 7.Bölge Müd., Afyonkarahisar, Türkiye \\ ${ }^{3}$ Afyon Kocatepe Üniversitesi, Teknoloji Fakültesi, Makine Mühendisliği Bölümü, Afyonkarahisar, \\ Türkiye \\ *cgurer@aku.edu.tr
}

(Alınıs/Received: 23.01.2021, Kabul/Accepted: 29.03.2021, Yayımlama/Published: 31.07.2021)

Öz: Tüm dünyada, konvansiyonel hatlarda olduğu gibi yüksek hızlı demiryolu hatlarında da balastlı üstyapı yaygın olarak kullanılmaktadır. Bununla birlikte yüksek hızlı hatların gelişmesi ve trenlerin yük kapasitelerinin artması demiryolu üstyapısındaki balast ve taban zemini arasındaki granüler tabakalara daha farklı malzemelerden yapılmış alt tabakaların (altbalast) eklenerek projelendirilmesini zorunlu kılmaktadır. $\mathrm{Bu}$ sayede demiryolu üstyapısının servis ömrü uzatıldığı gibi bakım maliyetlerinin de düşürülmesi sağlanmış olacaktır. Bu çalışma kapsamında alt balast tabakası yerine asfalt tabaka kullanımı Türkiye'de uygulanan bir tip kesit üzerinde, yüksek hızlı hat dingil yükü ve asfalt malzemenin farklı mevsimlerdeki özelliklerine göre sonlu elemanlar metoduyla (SEM) modellenerek çözümlenmiş ve elde edilen sonuçlar karşılaştııılmışıtır. Asfalt kaplamalardan oluşan alt balast tabakalarının yüksek hızlı hatlarda kullanılmasının taban zeminindeki deformasyonları ve gerilmeleri azaltacağı, yol güvenliğinin artmasını sağlayacağı ve her bölgede bulunması güç olan kaliteli balast malzemesine olan ihtiyacı da azaltacağı sonuçlarına ulaşılmıştır.

Anahtar kelimeler: Yüksek hızlı demiryolu hatları, Altbalast tabakası, Asfalt altbalast tabakası, SEM

\section{Investigation of Using Bituminous Mixture Instead of Granular Sub-Ballast Layer in High-Speed Rail Tracks with Finite Element Method}

\begin{abstract}
Rail track with granular ballast layer is widely used all over the world in high-speed railway lines as in conventional lines. However, the development of high-speed lines and the increase in the load capacity of the trains compulsory to design the sub-ballast made of different materials in the granular layers between the ballast and the track bed in the railway track. In this way, the service life of the railway track will be extended and also maintenance costs will be reduced. In this study, using asphalt layer instead of the granular sub-ballast layer under a rail track section applied in Turkey modelled with finite element method (FEM) under TCDD high-speed line axle loads and also using different asphalt materials features of the seasons and the obtained results were compared. It was concluded that the use of asphalt pavements in sub-ballast layers of high-speed lines will reduce deformations and stresses on the subgrade layer, increase rail track safety and reduce the need for quality ballast materials that are difficult to find in every region.
\end{abstract}

Keywords: High speed railway lines, Sub-ballast layer, Asphalt sub-ballast layer; FEM

\section{Giriş}

Ulaştırma sistemleri ve hizmetleri modern ekonomilerin ve toplumsal gelişmenin temel öğelerinden biridir. Son yıllarda yapılan yüksek hızlı hatlar ile Türkiye, sayılı hızlı tren işletmecisi ülkeden biri haline gelmiştir [1]. Halen inşaat halinde olan birçok yüksek hızlı demiryolu güzergahı bulunmaktadır. Konvansiyonel hatlarda olduğu gibi yüksek hızlı demiryolu hatlarında da balastlı üstyapı dünyada yaygın olarak kullanılmaktadır. Bununla birlikte yüksek hızlı hatların 
gelişmesi ve trenlerin yükleme kapasitelerinin artması demiryolu üstyapısındaki balast ve taban zemini arasındaki granüler tabakalara, farklı malzemelerden oluşmuş alt tabakaların (Altbalast) eklenerek projelendirilmesini zorunlu kılmaktadır. Bu sayede demiryolu üstyapısının servis ömrü uzatıldığı gibi bakım maliyetlerinin de düşürülmesi sağlanmış olacaktır. Yüksek hızlı hatlarda hızın etkisinden kaynaklanan titreşim vb. nedenlerden ve artan yükleme kapasitelerinden dolayı geleneksel granüler tabakalardan daha kalın üstyapı tabakası kullanımı gerekebilir. Bu durumda önemli miktarlarda yüksek kaliteli agregaya gereksinim durulur. Genellikle balast agregası olarak bazalt, granit, diyorit, dolomit ve andezit gibi sert kayaçlar tercih edilir [1]. Tüm dünyadaki kayaç rezervlerinin \%10' dan azının volkanik kökenli olduğu göz önüne alınırsa, yüksek hızlı hatlarda altbalast tabakalarında niçin asfalt kaplama gibi daha rijit tabakaların kullanılması gerekliliği daha iyi anlaşılabilir [2]. Yük trenlerinde $217 \mathrm{~km} / \mathrm{sa}$ ve yolcu trenlerinde $270 \mathrm{~km} / \mathrm{sa}$ üzerindeki hızlar (kritik hızlar), statik yüklere göre daha büyük deformasyonlara neden olan rezonansa sebep olur [4]. Yapılan araştırmalar, altyapıda kritik tren hızları yüzünden yol yatağında ve dolgularında kuvvetli titreşimlerin oluşabileceğini ve bunun da kritik şekil değiştirmelere neden olabileceğini göstermiştir [4]. Tren hızı "kritik hız" a ulaştığında büyük şekil değiştirmeler oluşabilir. Bu hareketler üstyapının yapısal bütünlüğü ve seyir güvenliği için tehlikeli olabilir, dolayısıyla yol bakım maliyetlerini yükseltir. Dolayısıyla yoldaki şekil değiştirmeleri kabul edilebilir düzeylerde sınırlayacak, dinamik bir rijitlik sağlayacak demiryolu üstyapı tasarımının hayati önemi bulunmaktadır [4]. Bu nedenle, alt katmanların kalınlığının azaltılması ve yol geometrisinin bozulmasının asgariye indirilmesi için çözüm olarak karayolu kaplamalarında yaygın olarak kullanılan sıcak karışım asfalt tabakanın uygulanması önerilebilir. Yağışların etkisiyle üstyapı dolgularında görülen göçüklerin ve nivelman bozukluklarının kazalara neden olabileceği belirtilmiştir [5]. Balast ve alt tabakalarda asfalt, altbalast olarak bilinen, geleneksel granüler tabakanın yerine birçok ülkede yaygın olarak kullanılmaktadır. ABD, İtalya, Japonya, Avusturya, Fransa ve İspanya gibi ülkelerin yüksek hızlı demiryolu hatlarında kullanılmaktadır [6]. Altbalast tabakalarında asfalt tabaka genellikle $12-15 \mathrm{~cm}$ kalınlıkta uygulanır ve maksimum agrega büyüklüğü 22-25 mm olan yoğun dereceli asfalttan oluşur [6]. Asfalt, genellikle karayollarında kullanılanla aynı özellikte tasarlanır, ancak alt balast uygulaması için bitüm içeriği karayolları için kullanılan optimum değere göre $\% 0,5$ oranında arttırılır. Ayrıca, hava boşluğu yüzdesi, balast boyunca geniş bir alana basınç uygulandığından, tekerlek izi deformasyonu problemlerini önleyebilecek geçirimsiz bir tabaka olarak kullanılmak üzere \%1-3'e düşürmektedir [7]. "Balastsız Asfalt Kombinasyonu" demiryolu üstyapı yatağı, nispeten kalın bir asfalt tabakası ve alt tabakadaki granüler altbalast üzerine yerleştirilmiş travers veya döşeme şeklindeki traverslerden (slab track) oluşur. Bu kalınlaştırılmış bölümler, balast katmanının yokluğunu telafi eder. Traverslerin, monoblok veya iki bloklu, kullanılan döşeme şeklindeki traverslerin ve asfalt yüzey profilinin tam tasarım ve konfigürasyonu, tercih edilen özelliklerin bir fonksiyonu olarak önemli ölçüde değişmektedir. Taban zemininin yumuşaması, özellikle titreşimle birlikte, büyük sorunlara neden olabilir. Bu nedenle Japonya ve İtalya'daki yüksek hızlı hatlarda, taban zemini üzerinde, 5 ila $8 \mathrm{~cm}$ kalınlığındaki su geçirmez asfalt tabakası kullanılmaktadır. Taban zemini üzerindeki gerilimleri dağıtmak ve azaltmak için asfalt betonu tabaka kalınlığı 15-20 cm'ye kadar yükseltilebilir (Şekil 1) [8-9, 10].

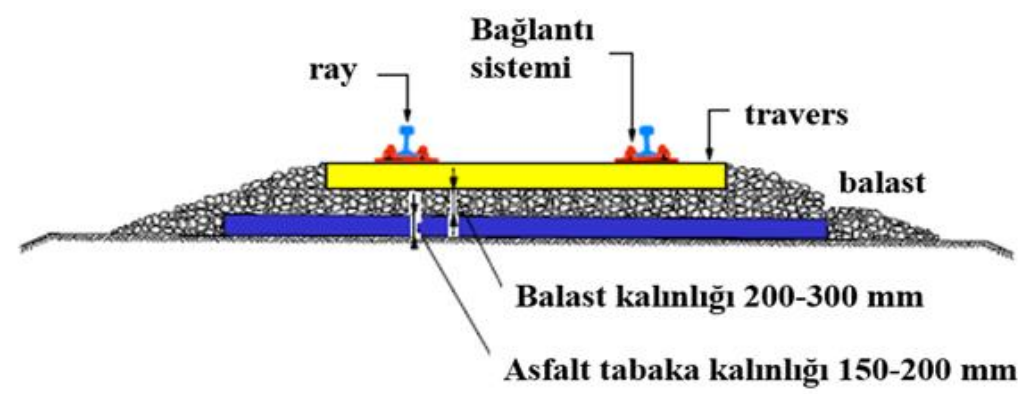

Şekil 1. Asfalt betonu ile güçlendirilmiş demiryolu üstyapısı [9]. 
Bu tip asfalt tabaka uygulamalarıyla üstyapının ağır bakımı da geciktirilmiş olur. Şekil 2' de İtalya'da yüksek hızlı demiryolu hattında asfalt kaplama tabakasının serilme işlemi görülmektedir.

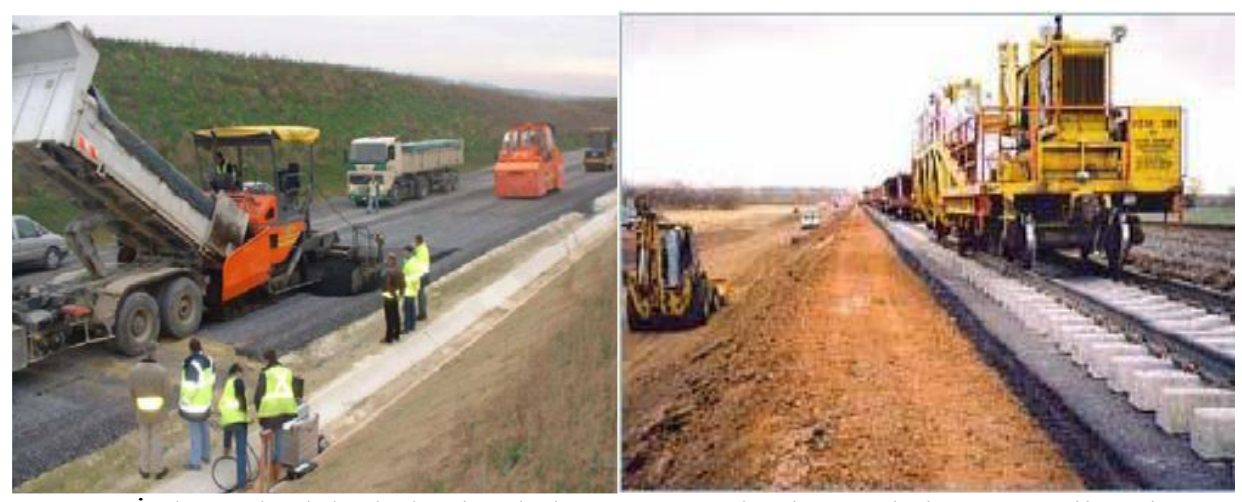

Şekil 2. İtalya yüksek hızlı demiryolu hattına asfalt kaplama tabakasının serilmesi [11].

Asfalt tabakaları, nispeten yüksek dingil yükleri ve yüksek brüt tonajlar için tasarlanan yeni demiryolu üstyapılarının yapımında büyük avantajlar sunabilir. Ek olarak, yolcu hizmetleri için tasarlanmış geleneksel demiryolu üstyapılarında takviye katmanlarının kullanılması, yol geometrisinin korunmasını sağladığı gibi bakımlarda da azalma sağlar. Geleneksel granüler altbalast tabakası yerine asfalt karışım kullanımının sağladığı avantajlar şu şekilde sıralanabilir:

- Azaltılmış titreşim ve gürültü seviyeleri,

- Azaltılmış kesitsel kalınlık,

- Azaltılmış taban zemini yorulmasından dolayı altyapıda azaltılmış kullanım ömrü maliyeti,

- Üstyapı taşıma kapasitesinin homojenizasyonu ve daha iyi balast tutma,

- İyileştirilmiş drenaj nedeniyle daha az balast kirlenmesi ve

- Artan modül ve homojenlik nedeniyle artan yapısal güvenilirlik ve güvenlik [7, 10].

1980'lerin başından beri, ABD demiryolu üstyapılarında destek katmanı olarak sıcak karışım asfalt uygulanmakta ve diğer ülkelerde de giderek uygulanması artmaktadır [12]. Genel olarak karayolu yapımı için kullanılana benzer şekilde asfalt tabakası, demiryolu üstyapısını klasik tüm granüler demiryolu üstyapılarından ayırır [12]. Bu gelişme, demiryolu trafik hacimlerinde, tonmil kapasitelerinde, dingil yüklemelerinde ve dünya genelinde yaşanmakta olan tonajlarda benzeri görülmemiş bir büyümeye uyum sağlamak için daha yüksek kalitede ve daha dayanıklı demiryolu üstyapı ve destek yapılarını sağlama konusundaki zorluklara cevap vermektedir. Asfalt betonu, iyi taşıma kapasitesi, su geçirmezlik, şok emilimi ve gürültü azaltma avantajlarına sahip karayolu ve havaalanı kaplamalarının yapımında kullanılan geleneksel bir malzemedir. Çin'deki hızlı tren yollarının hızla gelişmesiyle birlikte, yüksek hızlı demiryollarını destekleyen yük taşıma altyapısı drenaj, yerleşim ve yapısal yorulma gibi problemlerle karşı karşıya kalmaktadır. Son yıllarda, Çin yüksek hızlı demiryolunun demiryolu altyapısını inşa etmek için asfalt betonu kullanılmaktadır [13, 14]. Sol-Sánchez ve diğerlerine [15] göre demiryolu üstyapılarında asfalt alt balast kullanımı, üstyapı dayanımını artırmak için uygun bir çözüm olarak kabul edilir. Bununla birlikte, yaygın olarak uygulanması için, bu malzemenin çeşitli servis koşulları altında yerine getirmesi gereken ana gerekliliklere göre etkinliğini değerlendirmek için derinlemesine çalışmalara ihtiyaç vardır. Paixão ve diğerleri [16], farklı yükleme koşulları altındaki ve demiryolu üstyapılarında kullanılan geo malzemelerin lineer olmayan davranışları üzerine bir çalışma gerçekleştirmişlerdir. Bouraima ve diğerlerine [14] göre asfalt betonu ile güçlendirilmiş taban zemini yatağı ray yapısının düşey titreşimini azaltabilir. Ayrıca ivme genliğinin azalmasının, gürültünün de azalmasını sağlayacağı sonuçlarına ulaşılmıştır. Güler ve Aksop [17] 
yaptıkları çalışmada, balast tabakası veya beton plak üzerine oturan ray ve traverslerden oluşan yapıyı elastik yatağa oturan kiriş olarak sonlu elemanlar yöntemiyle iki ve üç boyutlu olarak modelleyerek analiz etmişlerdir.

Bu makale çalışması kapsamında alt balast tabakası yerine asfalt tabaka kullanımı, Türkiye'de uygulanan bir yüksek hızlı hat (YHT) tip kesit üzerinde, YHT dingil yüklerine göre, asfalt ve granüler alt balast tabakalı demiryolu üstyapısı için sonlu elemanlar metoduyla modellenerek çözümlenmiştir. Asfalt kaplama alt balast tabakalarının yüksek hızlı hatlarda kullanılmasının taban zeminindeki deformasyonlanı ve gerilmeleri azaltacağı, yol güvenliğinin artmasını sağlayacağı ve her bölgede bulunması güç olan, volkanik kayaç kökenli, granüler alt balast malzemesine olan ihtiyacı da azaltacağı sonuçlarına ulaşılmıştır.

\section{Metot}

\subsection{Materyal}

$\mathrm{Bu}$ çalışmada, son zamanlarda demiryollarında kullanımı giderek yaygınlaşan asfalt malzemesinin yüksek hızlı hat demiryolu üstyapısında, altbalast tabakasında kullanımının granüler malzeme kullanımına oranla avantaj ve dezavantajları bir SEM programı olan ANSYS ile araştırılmıştır. Analizlerde, TCDD, YHT hatlarında uygulanan standart dingil yükü $225 \mathrm{kN}$ kullanılmıştır. SEM analizinde kullanılan YHT demiryolu üstyapısı model geometrisi Şekil 3' te görülmektedir.

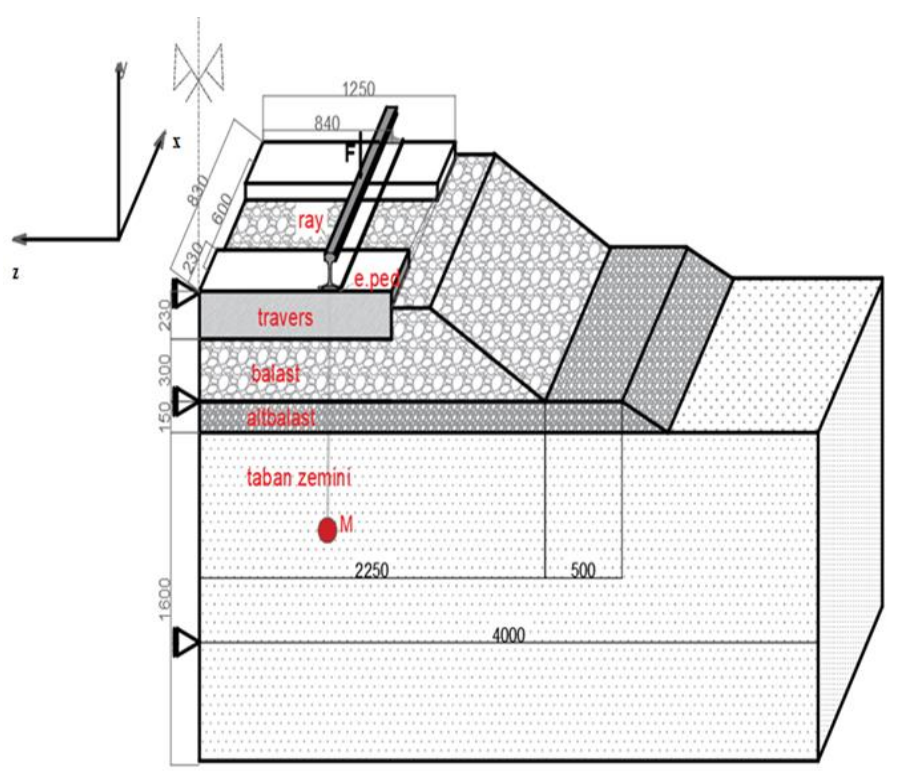

Şekil 3. TCDD standardına uygun dizayn edilmiş üstyapı geometrisi [18]

Tablo 1'de yüksek hızlı hat demiryolu üstyapısının tabakalarının mekanik özellikleri verilmiştir. Dingil yükü sistemde ray yüzey alanına dik uygulanmıştır. Sistem yatayda sabitlenirken düşeyde harekete izin verilmiştir. Taban zemini tabakası alttan sabitlenmiştir. Uygulanan dingil yükü tekil yük olup y ekseni boyunca (basınç kuvveti) düşey doğrultudadır.

\subsection{Yöntem}

ANSYS, sonlu sayıda geometriye ayrılabilen elemanların her birinin geometrisinin kendi içinde çözümlenebildiği, farklı malzeme özelliklerinin atanabildiği ve boşluklu yapıları tanımlarken kolaylıkla çözümleme yapılabildiği için birçok numerik yöntem yazılımından daha avantajlı bir 
programdır. ANSYS programında Kartezyen, küresel, silindirik olmak üzere 3 tip küresel koordinat sistemi bulunmaktadır. Bazı durumlarda yerel koordinat sistemlerine de ihtiyaç duyulabilir. Bu sistemler model geometrisinin oluşturulmasında kullanılır. Bunların dışında düğüm noktalarının serbestlik derecelerinin yönlerini belirlemek amacıyla nodal koordinat sistemi, elemana ait tanımlama ve sonuç görüntülemek için eleman koordinat sistemi, sonuç verilerinin belli bir sistemde sunulması için sonuç koordinat sistemi kullanılır.

Tablo 1. Malzemelerin mekanik özellikleri

\begin{tabular}{cccc}
\hline Malzeme & $\begin{array}{c}\text { Elastiste } \\
\text { Modülü E } \\
(\mathrm{MPa})\end{array}$ & $\begin{array}{c}\text { Poisson } \\
\text { Oranı } \\
(v)\end{array}$ & Kaynak \\
\hline Ray & 206000 & 0,30 & {$[19]$} \\
Elastik ped & 1000 & 0,45 & {$[20]$} \\
Travers & 25500 & 0,20 & {$[19]$} \\
Balast & 200 & 0,25 & {$[19]$} \\
$\begin{array}{c}\text { Alt Balast } \\
\text { (Balast) }\end{array}$ & 115 & 0,30 & {$[21]$} \\
$\begin{array}{c}\text { Alt Balast } \\
\text { (Asfalt }\end{array}$ & 9600 & 0,45 & {$[21]$} \\
Standart) & & & \\
$\begin{array}{c}\text { Zemin 2 } \\
\text { (Orta) }\end{array}$ & 80 & 0,40 & {$[1]$} \\
\hline
\end{tabular}

Programa başlamadan önce nasıl bir modele ulaşılmak istendiği belirlenerek, uygulama aşamasında model geometrisi, kullanılacak malzeme özellikleri, sınır şartları gibi veriler tanımlanır ve yükleme yapılır. Elde edilen sonuçlar yorumlanarak sistem analiz edilir.

Raylı sistemlerde, ray uzunluğu fazladır ve sonlu elemanlar metodu analiz programlarında bu kadar büyük bir modelin kullanımı çözüm süresini uzatmaktadır. Bu nedenle ray uzunluğu gerçekte kullanılan ray uzunluğundan daha kısa modellenmiştir. Bundan dolayı sınır şartlarına dikkat edilmelidir [22].

Şekil 3.' te TCDD standartlarına uygun tasarlanan modelin kesit detayları, Tablo 3' te ise seçilen malzemelerin mekanik özellikleri verilmiştir. Tanımlanan dingil yükü tekil yük olup bu basınç kuvveti ray yüzey alanına dik uygulanmıştır.

Şekil 4.' te model, her biri 30 mm kenar boyutlarında 188402 elemana ayrılmış ve 770672 adet düğüm noktası elde edilmiştir. Modelde taban zemini tabakasının en alt yüzeyi sabitlenirken yan yüzeyler ise yatayda sabitlenip düşeyde serbest bırakılmıştır. Daha sonra, ray üzerinde bir temas yüzeyi oluşturulup o alan üzerindeki noktaya düşey tekil yük uygulanmıştır.
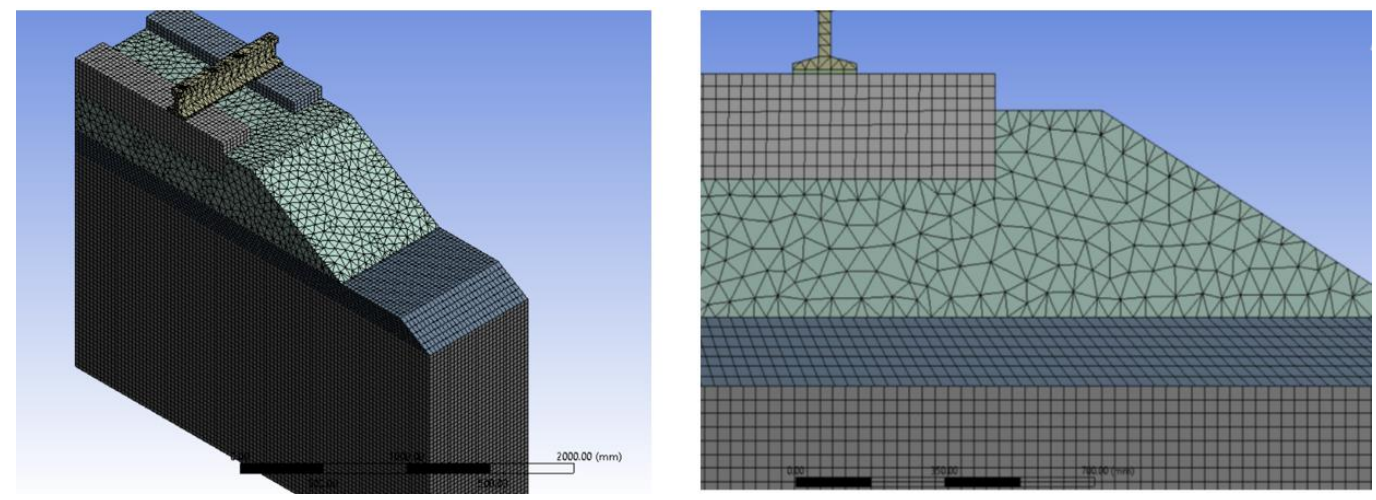

Şekil 4. Modelin sonlu elemanlara ayrılması 
Tablo 2'de değişen zemin şartlarında sistem davranışlarını kıyaslamak amacıyla seçilen farklı özellikte zemin malzeme özellikleri modellemede kullanılmıştır. Tablo 3'te ise sıcaklık farkından kaynaklanan malzeme özelliklerindeki değişimin sistem davranışına etkisini görmek amacıyla seçilen asfalt malzemenin farklı iklimlerdeki özellikleri verilmiştir.

Tablo 2. Zemin malzemelerin mekanik özellikleri [1]

\begin{tabular}{ccc}
\hline $\begin{array}{c}\text { Taban Zemini } \\
\text { Koşulları }\end{array}$ & $\begin{array}{c}\text { Elastisite } \\
\text { Modülü E } \\
(\mathrm{MPa})\end{array}$ & $\begin{array}{c}\text { Poisson } \\
\text { Oranı }(v)\end{array}$ \\
\hline Zemin 1 (Kötü) & 35 & 0,40 \\
Zemin 2 (Orta) & 80 & 0,40 \\
Zemin 3 (İyi) & 140 & 0,40 \\
Zemin 4 (Çok iyi) & 200 & 0,40 \\
\hline
\end{tabular}

Tablo 3. Asfalt malzemelerin farklı iklimlerde mekanik özellikleri [21]

\begin{tabular}{ccc}
\hline Malzeme & $\begin{array}{c}\text { Elastisite } \\
\text { Modülü } \\
(\mathrm{MPa})\end{array}$ & $\begin{array}{c}\text { Poisson Oranı } \\
(v)\end{array}$ \\
\hline Altbalast (Yaz) & 2564 & 0,45 \\
Altbalast (İlkbahar) & 4812 & 0,45 \\
Altbalast (Sonbahar) & 8618 & 0,45 \\
Altbalast (Kış) & 15582 & 0,45 \\
\hline
\end{tabular}

\section{Bulgular}

Şekil 5' te kötü özelliklere sahip bir taban zemini, en yaygın kullanılan $150 \mathrm{~mm}$ altbalast kalınlığ 1 ve $225 \mathrm{kN}$ dingil yükü için granüler malzeme ile asfalt malzemeden oluşan altbalast tabakası davranışları, altbalast tabakası ile taban zemini arasında tanımlanan yatay hat boyunca kıyaslanmıştır.

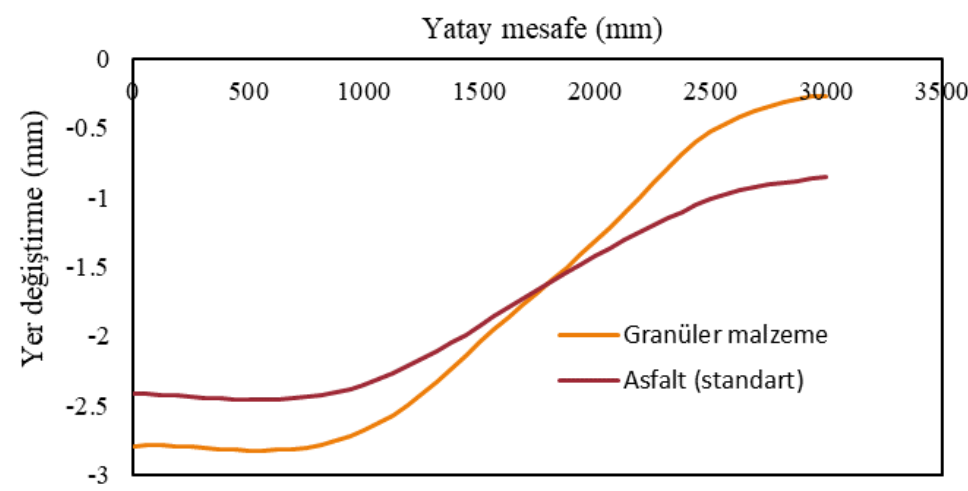

Şekil 5. $150 \mathrm{~mm}$ altbalast tabakasında kullanılan, granüler malzeme ile asfalt malzemelere ait düşey yer değiştirmelerin değişimi.

Şekil 6 ve 7'de granüler altbalast ve asfalt altbalast tabakaları için aynı yükleme şartlarında demiryolu üstyapısındaki yer değiştirmeler görülmektedir. Altbalast tabakasında asfalt malzemesi kullanıldığında maksimum yer değiştirme $2,68 \mathrm{~mm}$, granüler malzeme kullanıldığında ise 3,06 mm yer değişiminin olduğu belirlenmiştir. Sowmiya ve arkadaşları [23], SEM analizi neticesinde taban zemininde 1,68 mm'lik bir deformasyon değeri rapor etmişlerdir. Sol-Sánchez ve arkadaşları [15] demiryolu altyapısından asfalt altbalast kullanımını araştırmış ve benzer şekilde asfalt altbalast tabaksında daha düşük yer değişimi değerleri elde etmişlerdir. 


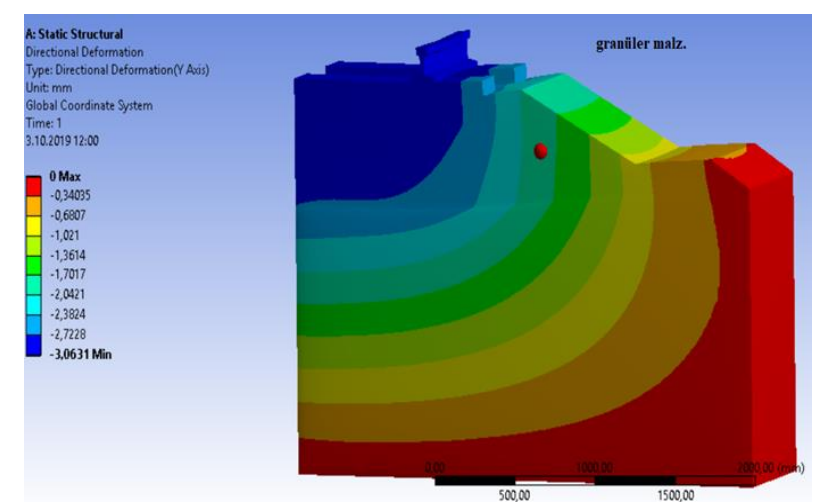

Şekil 6. $150 \mathrm{~mm}$ granüler altbalast tabakalı üstyapıdaki düşey yer değiştirmeler

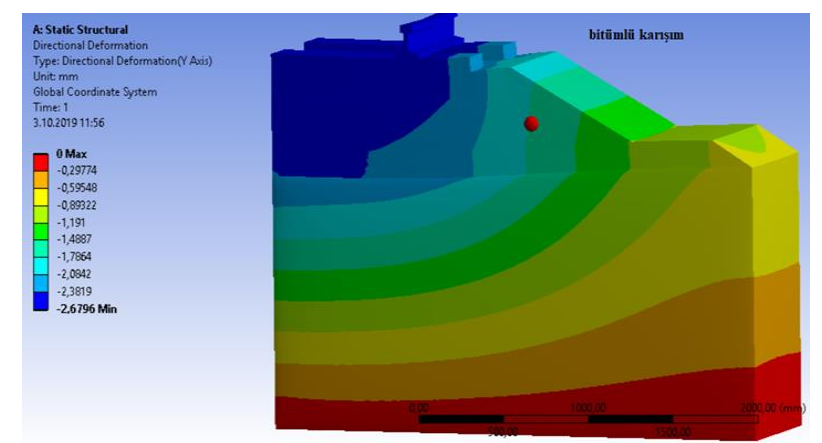

Şekil 7. $150 \mathrm{~mm}$ asfalt alt balast tabakalı üstyapıdaki düşey yer değiştirmeler

Granüler malzeme yerine kullanılacak asfalt altbalast tabakasının iklim şartlarına göre elastisite modüllerinde farklılıklar olacaktır. Bu durum asfalt tabakada kullanılan bitüm malzemesinin sıcaklığa bağlı olarak viskoelastik plastik davranış sergilemesinden kaynaklanır. Sıcaklık azaldıkça asfalt kaplamanın esnekliğinin de azalması beklenir. Elde edilen sonuçlar da bu durumu doğrulamaktadır. Kötü zemin şartlarında, $150 \mathrm{~mm}$ kalınlığındaki bir altbalast tabakası için seçilen malzemelerin mutlak değerce maksimum yer değiştirme miktarları Şekil 8'de verilmiştir. Şekil 8' de ayrıca asfalt altbalastın farklı mevsimlerdeki yükleme altındaki davranışları da görülmektedir. Uygulamada modifiye bitümle asfalt altbalast üretimi bu farklılıkların daha da azalmasını sağlamaktadır.

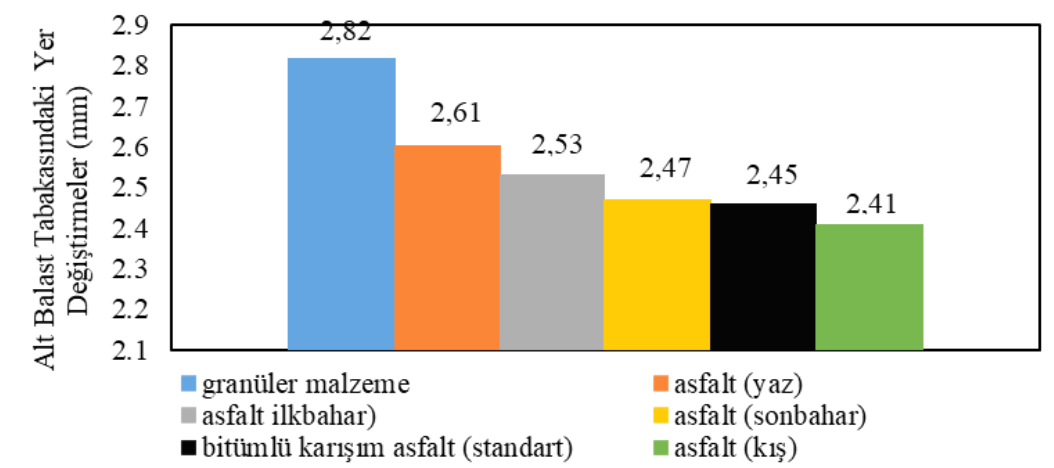

Şekil 8. Farklı mevsimlerde asfalt altbalast tabakasındaki düşey yer değiştirmeler

Taban zemini malzemesinin değişmesi üstyapı tabakalarındaki basınç ve çekme gerilmelerini de doğrudan etkilemektedir. Bu durum SEM ile birçok araştırmacı tarafından doğrulanmıştır [13, 14 , 16, 24 -26]. Oğul ve diğerleri [27] yaptıkları çalışma neticesinde bir dolgunun deforme olabilir 
zemin üzerine inşa edilmesi durumunda toplam oturmaların zeminin deformasyon durumuna bağlı olarak artacağını göstermişlerdir.

Asfalt ve granüler balast malzemeleri temelde birbirinden farklı mekanik özelliklere sahip malzemeler olduğu için mekanik davranışları da farklılıklar göstermektedir. Şekil 9'da verilen modelde düşey hat boyunca tanımlanan eğri görülmektedir. Şekil 10' da ise bu eğri üzerindeki temel tabakasının ortasında tanımlanan bir M noktası ile, 112,5 kN düşey yük altında, $150 \mathrm{~mm}$ kalınlığındaki granüler altbalast ve asfalt alt temel altındaki farklı taban zemini koşullarında oluşan gerilmeler kıyaslamalı olarak verilmiştir. Yüksek hızlı hatlarda taban zemini koşullarına göre farklı alt balast tabakalarında oluşan basınç gerilmelerinin Rose ve diğerleri [6] bulgulariyla yakın olduğu görülmüştür. Asfalt altbalast tabakalı demiryolu üstyapılarında 5 ila $11.5 \mathrm{MPa}$ arasında taban zemini düşey basınç gerilmesi rapor etmişlerdir.

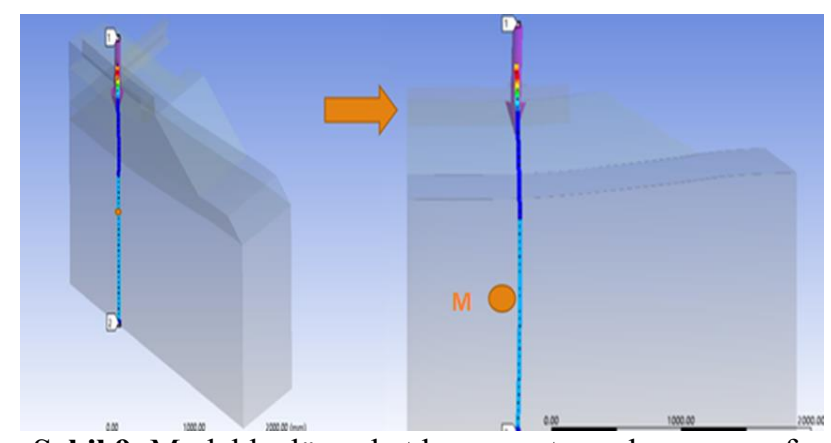

Şekil 9. Modelde düşey hat boyunca tanımlanan mesafe

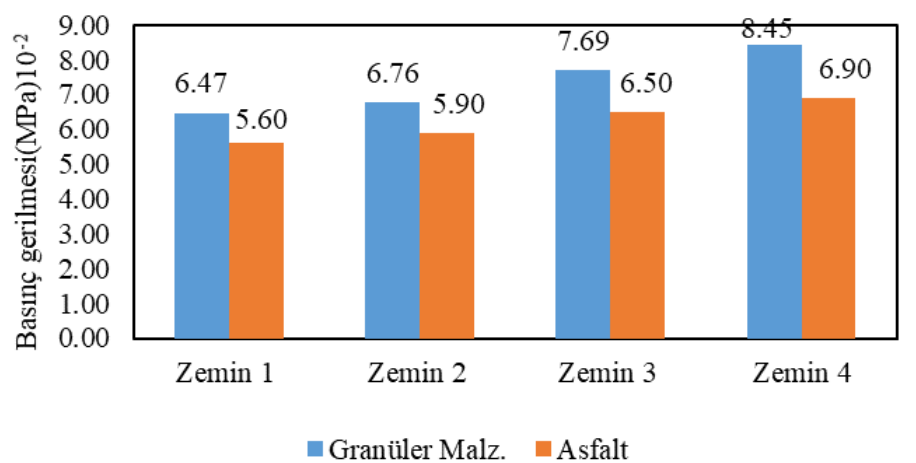

Şekil 10. Yüksek hızlı hatlarda taban zemini koşullarına göre farklı altbalast tabakalarında oluşan basınç gerilmeleri

\section{Sonuç}

Yapılan çalışmanın sonucunda elde edilen verilere göre; altbalast tabakasında granüler malzeme yerine asfalt kullanımı, taban zemini üzerindeki gerilmelerin ve yer değişimlerinin azalmasını sağlamıştır. Özellikle granüler balast ve altbalast tabakaları için bazalt, granit gibi kayaçların kullanıldığı ve belirtilen kökendeki kayaç rezervlerinin de ülkemizde ve tüm dünyada sınırlı olduğu göz önüne alındığında, altbalast tabakası gibi tabakalarda asfalt karışım kullanımı hattın stabilitesini korumayı sağlayacaktır. Kireçtaşı kullanılarak asfalt üretimiyle istenilen altbalast özellikleri kolaylıkla karşılanabilecektir. Ayrıca taban zemini malzeme türünün, deformasyon ve gerilmeler üzerinde, diğer parametrelere göre daha etkili olduğu görülmüştür. Zemin iyileştirme yöntemlerinin yüksek maliyetleri değerlendirildiğinde, altbalast tabakasının asfalt olarak yapılması demiryolu üstyap1 performansını olumlu olarak etkileyecektir. İlgili literatürde belirtildiği gibi, altbalast tabakanın asfalt olması taban zeminini üstten sızan sudan korumak için geçirimsiz bir tabaka sağlanmasına katkıda bulunacaktır. Altyapının sağlam ve geçirimsiz olması üstyapının korunmasına ve seyir güvenliğine katkı sağlayacak ayrıca üstyapı bakım maliyetleri 
de azalacaktır. Bu makale çalışması neticesinde demiryolu altbalast tabakasında Çin, İtalya gibi ülkelerde kullanılan asfalt malzemenin granüler altbalast malzemelerine göre üstünlüğü SEM analizi sonuçlarıyla gösterilmiş ve ülkemizde de kullanılmasına kılavuz olmak için belli başlı avantajlarının altı çizilmiştir. Bundan sonraki çalışmalarda balast ve altbalast gibi tabakalarda kullanılabilecek asfalt malzemesinin özellikleri hem deneysel hem de SEM sonuçlanyla karşılaştırmalı olarak araştırılabilir.

\section{Kaynakça}

[1] C. Gürer, Demiryolu mühendisliği, Yayımlanmamış lisansüstü ders notları. Afyon Kocatepe Üniversitesi, Afyonkarahisar, 2018.

[2] AGÜB. Türkiye Agrega Sektör Raporu, İstanbul, 2007.

[3] Anonim, "Çorlu tren kazası inceleme ve değerlendirme raporu." Türkiye Mühendislik Haberleri, TMMOB İnşaat Mühendisleri Odası Ulaştırma Kurulu, 2018, pp. 22-38.

[4] N.S. Yalçın, ve A. Erel, "Yüksek hızlı demiryollarında altyapının önemi ve tasarım ilkeleri," 7. Ulaștirma Kongresi, İstanbul, 2017, pp. 323-343

[5] [Online]. Available: https://www.tmmob.org.tr/sites/default/files/imo.pdf, [Accessed March 22, 2021]

[6] J.G Rose, L.S. Bryson, "Hot mix asphalt railway trackbeds: trackbed materials, performance evaluations and significant implications," International Conference on Perpetual Pavements, Columbus, 2009, pp. 19-25

[7] J.G. Rose, P.F. Teixeira, P. Veit, "International design practices, applications and performances of asphalt/bituminous railway trackbeds," GEORAIL, Paris, France, 2011, pp. 1-23

[8] C. Esveld, Modern railway track. 2. edition, Delft University of Technology, Netherlands: MRTProductions, 2001

[9] C. Esveld, "Modern railway track," 2011. [Online]. Avaliable : http://esveld.com. [Accessed: April $16,2019]$

[10]T. A. Törer, "Yüksek hızlı hat demiryollarinda alt balast tabakası yerine bitümlü karışım kullanımının sonlu elemanlar yöntemi ile araştırılması", Yüksek Lisans Tezi, Fen Bilimleri Enstitüsü, İnşaat Mühendisliği A.B.D., Afyon Kocatepe Üniversitesi, Afyonkarahisar, 2019

[11] J.G. Rose, R.R. Souleyrette, "Asphalt railway trackbeds: recent design, applications and performance," AREMA, 2015.

[12] [Online]. http://www.asphaltmagazine.com [Accessed April 20, 2019]

[13]E. Yang, Y. Qiu, Q. Luo, "An asphalt concrete application for high-speed railway in China," 6th International Conference Bituminous Mixtures and Pavements, Thessaloniki, 2015

[14] M.B. Bouraima, E. Yang, Y. Qiu, "Mechanics calculation of asphalt concrete track- substructure layer and comparisons," American Journal of Engineering Research (AJER), vol. 6, no. 7, pp.280-287, 2017

[15] M. Sol-Sánchez, L. Pirozzolo, F. Moreno-Navarro, M.C. Rubio-Gámez, "Advanced characterisation of bituminous sub-ballast for its application in railway tracks: The influence of temperature," Construction and Building Materials, vol. 101, pp. 338-346, 2015, doi.org/10.1016/j.conbuildmat.2015.10.102

[16] A. Paixão, J. N. Varandas, E. Fortunato, R. Calçada, "Non-linear behaviour of geomaterials in railway tracks under different loading conditions," Procedia Engineering, vol. 143, pp. 1128-1135, 2016, doi: 10.1016/j.proeng.2016.06.147

[17]H. Güler, E.Y. Aksop, "Analysing railway substructure and superstructure by using finite element methods and dimensioning of track components," 5th International Symposium on Innovative Technologies in Engineering and Science (ISITES2017), Azerbaijan, Baku, 29-30 September, 2017

[18] UIC 719 R, Earthworks and Track Bed Construction for Railway Lines, 2018

[19] L. Li, S. Nimbalkar, R. Zhong, (2018) "Finite element model of ballasted railway with infinite boundaries considering effects of moving train loads and Rayleigh waves," Soil Dynamics and Earthquake Engineering, vol.114, pp.147-153, 2018, doi.org/10.1016/j.soildyn.2018.06.033

[20] M. Eroğlu, "Raylı sistemlerde ray ve teker arasındaki temas analizinin ansys ortamında incelenmesi," Lisans Tezi, Makine Mühendisliği Bölümü, Karabük Üniversitesi, Karabük, 2014

[21] J.G. Rose, B. Su, W.B. Long, "KENTRACK: A railway trackbed structural design and analysis program," AREMA Conference Proceedings, 2003

[22] Y. Özdemir, "Ray-teker temasında temas parametrelerinin incelenmesi," Demiryolu Mühendisliği, vol. 11, pp. 1-13, Jan. 2020 
[23] L.S. Sowmiya, J.T. Shahu, K.K. Gupta, "Three-dimensional finite element analysis of railway track," Indian Geotechnical Conference, IGS, Mumbai, Chapter \& IIT Bombay, 2010, pp.909-912

[24] J. Han, G.T. Zhao, XZ. Sheng, X.-S. Jin, "Study on the subgrade deformation under high-speed train loading and water-soil interaction," Acta Mechanica Sinica vol. 32, no. 2, pp. 233-243, 2015, doi: 10.1007/s10409-015-0522-6

[25] M. Esmaeili, A. Khodaverdian, H. K. Neyestanaki,S. Nazari, "Investigating the effect of nailed sleepers on increasing the lateral resistance of ballasted track," Computers and Geotechnics, vol. 71, pp. 1-11, 2016, doi:10.1016/j.compgeo.2015.08.006

[26] H. Heydari-Noghabi, J. Varandas, M. Esmaeili, J. Zakeri, "Investigating the influence of auxiliary rails on dynamic behavior of railway transition zone by a $3 \mathrm{~d}$ train-track interaction model," Latin American Journal of Solids and Structures, vol. 14, no. 11, pp. 2000-2018, 2017, doi: 10.1590/1679-78253906

[27] K. Oğul, U. Mutman, E. Poşluk, "Yüksek hızlı demiryollarında kullanılan yaklaşım dolgu modellerinin sayısal analiz ile değerlendirilmesi," Demiryolu Mühendisliği, no.10, ss. 46-53, Temmuz, 2019

\section{Özgeçmiş}

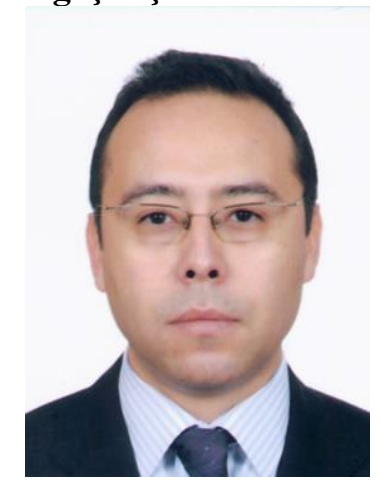

\section{Cahit GÜRER}

24.03.1976 tarihinde Afyonkarahisar'da doğmuştur. Lisans eğitimini Eskişehir Osmangazi Üniversitesinde, yüksek lisansını Afyon Kocatepe Üniversitesinde, Doktora eğitimini Süleyman Demirel Üniversitesi, İnşaat Mühendisliği, Ulaştırma Anabilim dalında tamamlamıştır.2013-2014 yılları arasında ABD Kansas State ve Iowa State Üniversitelerinde doktora sonras1 araştırmalarda bulunmuştur. Halen Afyon Kocatepe Üniversitesi, Mühendislik Fakültesi, İnşaat Mühendisliği, Ulaştırma Anabilim Dalında öğretim üyesi olarak çalışmaktadır. İlgi alanına giren araştırma konuları; Bitümlü karışım yol kaplamaları, sathi kaplamalar, akıllı ulaşım sistemleri ve demiryollarıdır.

E-Posta: cgurer@aku.edu.tr
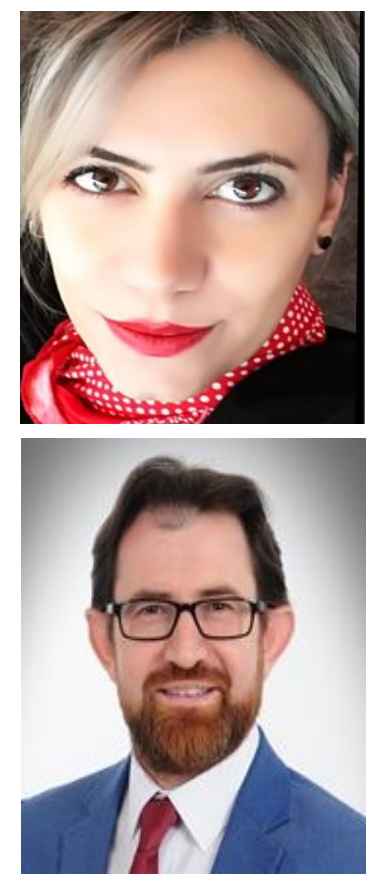

\section{Tuğçe AKILLI TÖRER}

27.05.1986 tarihinde İstanbul'da doğmuştur. Lisans eğitimini Yılddz Teknik Üniversitesinde, Yüksek Lisans eğitimini Afyon Kocatepe Üniversitesinde tamamlamıştır. Halen TCDD Genel Müdürlüğü/ Modernizasyon Dairesinde çalışmaktadır. İlgi alanına giren araştırma konuları Yüksek Hızlı Tren Demiryolu Hat Yapıs1, Altyapı, Sonlu Elemanlar Yöntemidir.

E-Posta: tugcetorer@gmail.com

\section{Kubilay ASLANTAŞ}

06.11.1974 tarihinde Sivas'ta doğmuştur. Lisans eğitimini Gazi Üniversitesinde, Yüksek Lisans Eğitimini Afyon Kocatepe Üniversitesinde, Doktora eğitimini ise Gazi Üniversitesi, Makine Eğitimi Anabilim Dalında tamamlamıştır. Afyon Kocatepe Üniversitesi, Teknoloji Fakültesi, Makine Mühendisliği Anabilim Dalında öğretim üyesi olarak çalışmaktadır. Mechanical Science and Engineering at University of Illinois Urbana-Champaign'de doktora sonrası araştırmalarda bulunmuştur. İlgi alanına giren araştırma konuları;Sonlu elemanlar ve Talaş kaldırma teorisidir.

E-Posta: aslantas@aku.edu.tr

\section{Beyanlar:}

Bu makalede bilimsel araştırma ve yayın etiğine uyulmuştur.

Tüm yazarların eşit oranda katkısı olmuştur. 